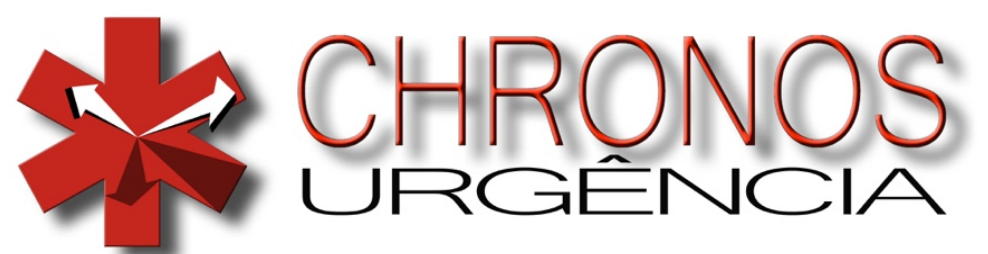

https://chronos.samu.fortaleza.ce.gov.br elSSN 2763-5872

\title{
Artigos
}

\section{Evolução na Formação de Facilitadores para Educação Permanente pelo Núcleo de Educação Permanente do SAMU 192 Regional Fortaleza}

\author{
Evolution in the Formation of Facilitators for Permanent Education by \\ the Núcleo de Educação Permanente of SAMU 192 Regional Fortaleza \\ (abstract: p. 15)
}

\section{Evolución en la Formación de Facilitadores de Educación Permanente por el Núcleo de Educação Permanente del SAMU 192 Regional Forta- leza (resumen: p. 15)}

D CLÁUDIO ROBERTO FREIRE DE AZEVEDO claudio.azevedo@samu.fortaleza.ce.gov.br

Núcleo de Educação Permanente do SAMU 192 - Regional Fortaleza

Rua Padre Guerra, 1350; Parquelândia. Fortaleza - Ceará CEP 60.455-365

(iD) JULIANA ARAÚJO DE MEDEIROS

jumedeiros@orion.med.br

Núcleo de Educação Permanente do SAMU 192 - Regional Fortaleza

\begin{abstract}
Objetivo: esse estudo visa apresentar a evolução das mudanças metodológicas na formação de profissionais para a educação permanente em saúde. Metodologia: trata-se de um estudo descritivo, de natureza qualitativa, baseado em análise documental sobre a Capacitação de Tutores e Facilitadores em Educação Permanente em Saúde no SUS, em execução pelo Núcleo de Educação Permanente do SAMU 192 Regional Fortaleza desde janeiro de 2013, capacitando profissionais da área da saúde para facilitar educação permanente em seus serviços. Resultados: a capacitação passou por cinco fases ao longo do tempo, integrando-se como atividade educacional da Secretaria Municipal da Saúde de Fortaleza e impulsionando a construção do Plano Municipal de Educação Permanente em Saúde. Considerações finais: percebeu-se uma evolução na abordagem metodológica e na ênfase do aprendizado, de uma formação mais técnica, para a implementação da Educação Permanente em Saúde no serviço, para uma formação reflexiva individual, uma reflexão do sujeito enquanto fomentador de mudanças onde quer que esteja. Passou-se a promover o desenvolvimento das habilidades de aprender a aprender, da autonomia e aprendizagem colaborativa, para promover a criatividade e, principalmente, para "aprender a Ser para poder ser com os outros como se é consigo mesmo".
\end{abstract}

Descritores: Capacitação de Professores; Educação Permanente; Serviços Médicos de Emergência.

Palavras-chave: Formação de Facilitadores; Educação Permanente; Urgência; Pré-hospitalar. 


\section{Introdução}

O Núcleo de Educação Permanente do SAMU 192 - Regional Fortaleza (NEP SAMUFor) configura-se como a instância responsável pela educação permanente de seus profissionais e, trabalhando integrado com a Coordenadoria de Educação em Saúde, Pesquisa e Programas Especiais (COEPP) da Secretaria Municipal da Saúde de Fortaleza, também por articular as ações necessárias de capacitação e de educação permanente para toda a Rede de Atenção à Urgência e Emergência (RUE) no município de Fortaleza, segundo determinado na Portaria SMS № 81, de abril de 2016, em seu artigo nono ${ }^{1}$ (p. 57).

Sua história remonta à época da criação do Programa S.O.S. Fortaleza, em meados de 1992, quando o Centro de Formação em Urgência (CEFUR) iniciava suas atividades em preparação dos profissionais que iriam atuar no atendimento pré-hospitalar de casos não-traumáticos em Fortaleza. Bastante ativo à época, no início das atividades do Programa S.O.S. Fortaleza o CEFUR trabalhava com o conceito de educação em serviço: "prática inerente ao processo de trabalho, composta por ações educativas no ambiente de trabalho para fazer com que o profissional consiga relacionar o que lhe está sendo transmitido à sua prática diária"2 (p. 336).

Com o lançamento do SAMU 192 - Fortaleza na assistência pré-hospitalar de urgência em 2004, em substituição ao já então Núcleo S.O.S. Fortaleza, surge o incentivo à criação dos Núcleos de Educação em Urgências (NEU), instituídos pelas Portarias GM/MS № 2048, de 05 de novembro de $2002^{3}$, e № 1863, de 29 de setembro de $2003^{3}$, essa última implantando a Política Nacional de Atenção às Urgências (PNAU).

Os NEU teriam a problematização como modelo pedagógico e seriam estruturas regionais de educação, voltadas mais à capacitação de profissionais da RUE loco-regional. No entanto, como os NEU nasceram junto com o componente SAMU e sua Central de Regulação das Urgências, ficaram fortemente ligados aos mesmos, restritos aos objetivos operacionais de formação e capacitação de profissionais do componente pré-hospitalar móvel.

O conceito inovador de Educação Permanente em Saúde (EPS) e de sua política, foram instituídos oficialmente em $2004^{4}$, mas os NEU, envolvidos com seus processos formativos, extremamente necessários à época, pouco se preocupavam com a mesma e pouco se articulavam com o restante dos componentes da RUE. Não foi diferente em Fortaleza e, mesmo dentro do SAMU 192 - Fortaleza, as atividades do novo órgão educacional NEU eram bastante insipientes, passando a exercer suas atividades como Educação Continuada ${ }^{2}$ (p. 334) para profissionais que, na sua maioria, já se sentiam capacitados para o atendimento pré-hospitalar pelo seu longo tempo de exercício profissional. Com isso, testemunhou-se um esvaziamento nas atividades educacionais no SAMU 192 - Fortaleza. 
A Educação Permanente difere da Educação Continuada por, diferente da perspectiva uniprofissional e tradicional dessa ${ }^{4}$ (p. 43-44), ser multiprofissional e estar incorporada no cotidiano do trabalho utilizando-se de "ferramentas que buscam a reflexão crítica sobre as práticas de atenção, gestão e formação [...], possibilitando mudanças nas relações, nos processos, nos atos de saúde e nas pessoas" (p. 49).

Diante desse cenário, de 20 a 23 de março de 2006, por ocasião do I Congresso Nacional da Rede SAMU 192 promovido pelo Ministério da Saúde, foi proposto que cada SAMU implantasse, de fato, seu núcleo específico denominado NEP (Núcleo de Educação Permanente), com o principal objetivo de promover a educação permanente dentro do serviço, deixando a instituição NEU para seus objetivos originais de capacitar toda a rede e recertificar todos os profissionais a cada dois anos, como previsto no Capítulo VII, item 1.4 da citada Portaria GM/MS № 2048/2002. Com isso, em 2006, apenas mudou-se o nome do núcleo educacional do SAMU 192 - Fortaleza para NEP.

Mesmo assim, o hiato com atividades educacionais incipientes perdurou até 2009. Em 17 anos de existência, muitas mudanças ocorreram no serviço, fruto de pressões externas e internas, resultando em um sem número de fluxos de trabalho, alguns institucionalizados e outros não, esses últimos de uso corrente e informal, mas não necessariamente eficazes e eficientes nem isentos de erros. Esses processos informais de trabalho contribuíam sobremaneira para os erros frequentes e, cristalizados, perpetuaram vícios que acompanharam as gerações de funcionários novos que surgiram.

Em dezembro de 2010 fez-se o primeiro e incipiente mergulho na tentativa de entender a educação de adultos, na oferta de um curso de Capacitação de Tutores e Preceptores em Urgência Préhospitalar (24h/aula) pelo NEP, com 3 encontros, utilizando a exposição dialogada como estratégia de ensino. Essa foi a primeira turma de capacitação de educadores no SAMU 192 - Fortaleza. Mesmo assim, ao longo do tempo notou-se que, apesar das capacitações existentes para ingresso no serviço e das recapacitações periódicas oferecidas, não havia êxito nas mudanças esperadas e diversos vícios antigos ainda permaneciam.

Apesar de municipal, pela Portaria GM/MS № 2.502, de 1을 de novembro de 2012³ , o SAMU 192 - Fortaleza é habilitado pelo Ministério da Saúde como "SAMU 192 - Regional Fortaleza" (SAMUFor). Com 20 anos, os desafios agora eram outros, uma vez que o tempo se encarregara de diversificar sobremaneira a forma de condução técnica nos atendimentos por parte dos profissionais do pré-hospitalar móvel e da Central de Regulação das Urgências de Fortaleza (CRUFor) e a educação continuada já não dava conta de lidar com esse desafio. Mais do que simplesmente criar capacitações e/ou instituir fluxos, diretrizes e protocolos, a reorganização do serviço implicava numa mudança de atitude de todos que o constituíam. 
Nesses seis anos de NEP, a resistência às mudanças nos processos e fluxos de trabalho informais, alguns já tecnicamente não mais recomendados pela literatura científica, foi a tônica. Diante da ansiedade da urgência por mudanças da gestão, algumas vezes essas mudanças foram forçadas, afundando os profissionais mais e mais em suas trincheiras e criando uma resistência ainda maior à mudança e ao próprio processo educativo em si mesmo, desperdiçando recursos e tornando os profissionais apreensivos e frustrados. E mais, apesar de incentivos e ameaças, as tentativas de reorganização podem ser simplesmente silenciadas por obstruções habilidosas de profissionais descontentes, reforçando o status quo vigente ${ }^{6}$ (p. 25-26).

Na busca de outras formas de implementar mudanças, deparou-se com a possibilidade de obtêlas através da educação permanente, utilizando metodologias ativas como forma envolvimento, motivação e engajamento dos trabalhadores no processo de gestão das mudanças e na elaboração de planos-proposta a partir de problemas da realidade do serviço. Assim, foi somente no final de 2012 que a coordenação do NEP formalizou um projeto aplicativo e pensou um modelo pedagógico que desse conta das mudanças organizacionais necessárias, processo esse que se iniciou na CRUFor 6 .

Desejava-se que a regulação médica primária no SAMUFor fosse aprimorada por meio da estratégia de educação permanente em saúde e o projeto traçou alguns passos a serem seguidos: a) sensibilização dos gestores do serviço da necessidade da implantação de uma educação permanente, no sentido de aprimorar a regulação médica do serviço; b) capacitação dos preceptores/gestores do NEP SAMUFor em metodologias ativas de ensino-aprendizagem; c) implementação de um Projeto de Educação Permanente, envolvendo os profissionais da CRUFor, visando o acompanhamento e a problematização das condutas no trabalho; d) implementação e avaliação contínua de mudanças esperadas; e) comunicação ampla dos resultados positivos alcançados, como forma de incentivo à consolidação das mudanças.

A EPS impõe o desenvolvimento de novas competências profissionais no ensinar, com o trabalho com metodologias ativas de aprendizagem ${ }^{7}$ (p. 153), e se caracteriza por focar a educação na vida cotidiana, transformando "situações diárias em aprendizagem, analisando reflexivamente os problemas da prática e valorizando o próprio processo de trabalho no seu contexto intrínseco"8 (p. 974).

Também defende a aprendizagem significativa como propiciadora de transformações para que o trabalho em saúde seja lugar de atuações críticas, reflexivas, propositivas, compromissadas e tecnicamente competentes $^{9}$ (р. 9). Isso impõe o desenvolvimento de um novo perfil de educador, que consiga facilitar o surgimento de um princípio teórico significativo: a autonomia do educando ${ }^{10,11}$ :

"Para fomentar esses processos, a EPS conta com a função de facilitador/a. Esse/a profissional tem como tarefa promover reflexões sobre o cotidiano do trabalho, em conjunto com 
a equipe, de forma que essa se aproprie dos impasses nos seus processos de trabalho, refletindo sobre as diversas dimensões da vida que os compõem e neles se reconhecendo, de modo a encontrarem formas de ação conjunta diante deles"12 (p. 8)

Daí a importância da capacitação dos educadores/gestores do NEP SAMUFor em metodologias ativas de aprendizagem, segundo passo do projeto aplicativo acima citado. Dessa forma, em janeiro de 2013 surge uma nova capacitação de educadores do NEP, agora com ênfase na facilitação com metodologias ativas de ensino-aprendizagem: a "Capacitação de Apoiadores Institucionais e de Educação Permanente em Saúde no Serviço". Em 2014-2015 essa capacitação se amplia para toda a Secretaria Municipal de Saúde (SMS) de Fortaleza, momento em que o NEP consolida sua Estratégia de Educação Permanente em quatro Eixos, incluindo em cada um estratégias de Educação Continuada e em Serviço, com capacitações, aperfeiçoamentos e treinamentos específicos em sessões clínicas: Eixo de Educação Permanente de Tutores e Facilitadores de Educação Permanente em Saúde; Eixo de Educação Permanente em Gestão de Situações de Urgência na Saúde; Eixo de Educação Permanente em Regulação no SUS; e Eixo de Educação Permanente em Suporte de Vida.

A principal atividade do Eixo I foi denominada de Estratégia de Capacitação e Aperfeiçoamento em Educação Permanente em Saúde no SUS (CAEPS-SUS) e tinha como objetivo principal o capacitar e aperfeiçoar profissionais em facilitação de processos educacionais que utilizassem metodologias ativas de ensino-aprendizagem, com competências para atuar como Tutores, Facilitadores e Apoiadores Institucionais em Educação Permanente em Saúde na SMS.

Também visava fortalecer a Política de Educação Permanente no município de Fortaleza, habilitar educadores ao uso de metodologias ativas de ensino-aprendizagem, qualificar atores sociais com competências para mudar a realidade existente através da Educação Permanente, implementar a Educação Permanente em Saúde (EPS) no âmbito da Secretaria Municipal de Saúde de Fortaleza (SMS), através da qualificação de educadores dos Núcleos de Educação Permanente e Apoiadores Institucionais, vinculados às Coordenadorias Regionais de Saúde no município de Fortaleza, e contribuir com a construção de cenários que propiciassem a reflexão permanente das equipes de saúde sobre suas práticas, visando ampliar as capacidades institucional e profissional de sistemas locais de saúde, na atenção à saúde, na gestão da clínica, na participação social e na formação em saúde.

A CAEPS-SUS ficou dividida em duas fases: Fase 1 de capacitação e Fase 2 de aperfeiçoamento. A Fase 1 objetivava a capacitação de educadores no uso de Metodologias Ativas e Participativas de Ensino-Aprendizagem (MAPEA), cujo grande diferencial estava na mudança de foco do processo educativo, que saia do ensino e passava a priorizar os processos de aprendizagem nos quais o educando se compromete com seu aprendizado por meio da identificação e análise de problemas, da capacidade 
de elaborar questões e de procurar informações para ampliá-las e respondê-las.

Na Fase 2 o foco era a implantação/implementação de Núcleos de Educação Permanente locais que pusessem em evidência o trabalho em saúde, uma intensa permeabilidade ao controle social, compromissos de gestão com a integralidade e a humanização, um aprofundamento no próprio desenvolvimento como educador e como pessoa humana e a produção de conhecimento que produzisse práticas concretas de cuidado de pessoas e coletividades.

Ambas as etapas foram criadas com encontros presenciais e atividades virtuais. Por meio dos encontros presenciais, propiciava-se a integração e a troca de experiências entre os participantes, potencializando a ação construtiva da educação permanente em saúde a partir de diversos disparadores, como situações-problema, narrativas reflexivas, vídeos curtos (clippings), filmes etc. As atividades virtuais buscavam estimular a reflexão sobre o próprio aprendizado e a capacidade de análise, avaliação e articulação de saberes, com vistas à implementação/consolidação da educação permanente em saúde.

A expansão da estratégia para toda a SMS consolidou o conceito da espiral educacional do processo de ensino-aprendizagem-aplicação a partir da exploração de um disparador educacional e dos princípios pedagógicos que lhe servem de base ${ }^{13}$, representado pela Figura 1:

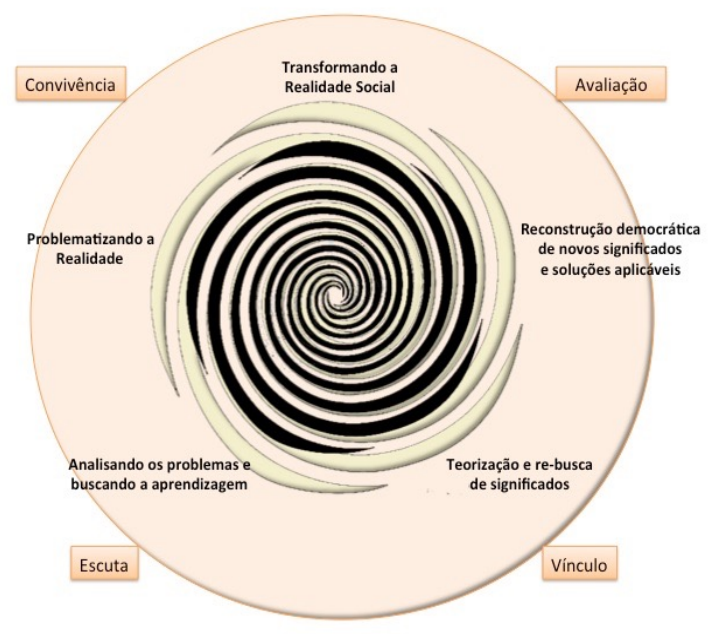

Figura 1. espiral de princípios educacionais do NEP SAMUFor. Fonte: NEP SAMUFor

Agora, trabalhando integrado com a Coordenadoria de Gestão do Trabalho e Educação em Saúde (CoGTES) da SMS, o processo pedagógico da Fase 1 impulsionou a construção do Plano Municipal de Educação Permanente em Saúde (PMEPS) pela mesma, culminando em sua publicação em $2018^{14}$.

O escopo deste estudo será delimitado pela Fase 1 da formação de tutores e facilitadores, por ser a atividade a mais tempo em execução e, por isso, com maiores mudanças em sua aplicação metodológica. Tem-se como objetivo apresentar a evolução e as modificações que foram acontecendo 
nessa primeira fase da CAEPS-SUS, desde seu início até os dias atuais. Este estudo justifica-se pela oportunidade de divulgar uma proposta de como profissionais da área da saúde podem ser capacitados como facilitadores de educação permanente em saúde, impulsionando a implementação local de Núcleos de Educação Permanente que fomentem as mudanças de prática nos serviços.

\section{Metodologia}

Trata-se de um estudo descritivo, de natureza qualitativa, baseado em análise documental sobre a Fase 1 da Estratégia de Capacitação e Aperfeiçoamento de Tutores e Facilitadores em Educação Permanente em Saúde no SUS (CAEPS - SUS), em execução pelo NEP SAMUFor desde janeiro de 2013, capacitando profissionais da área da saúde para facilitar educação permanente em suas unidades de saúde.

Esse estudo seguiu as determinações da Resolução CNS № 510/2016 e da Carta Circular № 166/2018-CONEP/SECNS/MS, que dispensam a exigência prévia de registro e avaliação pelo sistema CEP/CONEP a estudos que versem sobre aspectos relacionados às práticas no serviço em que sejam respeitados os preceitos relacionados à privacidade dos participantes, a confiabilidade dos dados e a dignidade humana.

Foram feitas pesquisas nos relatórios de gestão, de 2009 a 2020, no Planejamento Estratégico de 2013, nos Planos de Educação em Urgência (PEU), de 2014 a 2021, e nos Relatórios do Processo Ensino-Aprendizagem (PEA) das Turmas II a XXIII da referida capacitação de tutores e facilitadores, de 2013 a 2020, todos documentos administrativo-gerenciais do NEP SAMUFor.

\section{Resultados}

Para a implementação da educação permanente no serviço, fez-se necessária uma formação de profissionais educadores com perfil claramente apropriado para facilitar e tutorar esses encontros. As capacitações eram semipresenciais, com turmas de 12 a 15 educandos, com parte importante da carga horária se desenvolvendo de forma remota e chegando, em algumas turmas, a consumir mais da metade da carga-horária do curso.

Essas atividades virtuais incluíam a) participação em atividades como fóruns de diálogo, presentes na sala virtual do curso, hospedado no Sistema de Ensino-aprendizagem à Distância (SEaD) do NEP SAMUFor; b) atividades de busca de evidências em bases indexadas, denominadas Aprendizagem Autodirigida $(A A D) ; c)$ sínteses reflexivas para responder alguma questão norteadora temática, denominadas Tarefas de Dispersão (TD); d) registros individuais sobre a própria metacognição e construção individual do conhecimento, materializados como Portfólio Reflexivo (PR); e, por fim, e) confecção do 
trabalho final do curso, de natureza prioritariamente reflexiva, denominado de Trabalho de Conscientização do Percurso (TCP).

A primeira constatação foi que a capacitação apresentou várias mudanças durante seus 8 anos e 22 turmas, evoluindo da seguinte forma: Capacitação de Apoiadores Institucionais e Educação Permanente em Serviço (MAEA), em 2013-2015, Capacitação em Metodologias Ativas e Participativas de Ensino e Aprendizagem (MAPEA II), em 2016-2017, a Capacitação em Aprendizagem Significativa para o SUS (CAS-SUS I), em 2017, a Capacitação em Aprendizagem Significativa para o SUS II (CAS-SUS II), em 2018, e a Capacitação em Aprendizagem Ativa e Colaborativa para o SUS (CAAC-SUS), em 2020.

Nessa evolução, de 2013 a 2020, a matriz curricular do curso apresentou diversas mudanças, tanto em sua estrutura, Unidades Educacionais eram criadas, extintas ou tinham suas ênfases alteradas, quanto no conteúdo e número de encontros, ou até no número de facilitadores por turma. Todas as necessidades de mudanças foram constatadas em encontros de educação permanente com os educadores do NEP, onde as avaliações dos processos de ensino-aprendizagem das turmas encerradas fomentavam um replanejamento educacional para as próximas turmas.

O MAEA foi um curso intensivo de cinco semanas, com dois encontros semanais. A partir da Turma $V$, com o início da parceria com a CoGTES, seu conteúdo passou também a incluir princípios pedagógicos da Política Nacional de Educação Popular em Saúde e a capacitação passou a chamar-se MAPEA, alterando o seu público alvo, prioritariamente, para todos os profissionais da saúde da SMS.

Em 2016, por solicitação de profissionais do próprio SAMUFor, surgiu o MAPEA II como uma forma de curso mais breve que o seu antecessor (o agora MAPEA I), com menos encontros presenciais, agora semanais, que aconteceu em apenas duas turmas. Estreitando mais a parceria entre o NEP SAMUFor e a COGTES, surgiu o CAS-SUS I seguindo a frequência de encontros semanais já existente. Inaugurou a facilitação com dois educadores, também tendo turmas abertas para todos os profissionais da SMS. Após a publicação da PMEPS, em 2018, surgiu então o CAS-SUS II, visando capacitar profissionais aptos à implementação da referida política em suas próprias unidades de saúde.

Para manter aproximadamente a mesma carga horária, diminuindo a quantidade de encontros, os cursos aumentaram a sua carga-horária por encontro, incluindo a assistência de filmes educacionais, e também a sua carga horária virtual, principalmente às custas das TD. No MAPEA II e CAS-SUS I foram três os temas das TD: Arco de Maguerez, Aprendizagem Significativa e Portfólio Reflexivo. Já no CAS-SUS II, foram cinco: a) Avaliação e Portfólio Reflexivo; b) cadastro de profissionais da unidade de saúde na plataforma de ensino da SMS; c) construção de Narrativa Reflexiva sobre "Um Problema na Unidade"; d) construção de planejamento das ações de educação permanente da unidade de saúde; e e) montagem da "Instalação de Avaliação" do curso ao final do mesmo.

A seguir, a Tabela 1 mostra um resumo da estrutura dos cursos, suas turmas e cargas-horárias: 
Tabela 1. CAEPS-SUS - fase 1 de Capacitação de Tutores e Facilitadores

\begin{tabular}{|c|c|c|c|c|}
\hline CURSOS & MAPEA / MAPEA I & MAPEA II & CAS-SUS I & CAS-SUS II \\
\hline Unidades Educacionais e Turmas & II a XIII & XIV e XV & XVI a XVIII & XIX a XXII \\
\hline Pensando Metodologias & 2 encontros & 2 encontros & 2 encontros & 2 encontros \\
\hline Pensando Competências & 2 encontros & 1 encontro & 1 encontro & 2 encontros \\
\hline Pensando Habilidades & 2 encontros & 1 encontro & 1 encontro & 2 encontros \\
\hline Pensando Novas Estratégias & - & - & - & 3 encontros \\
\hline Pensando Novas Ferramentas & 4 encontros & 2 encontros & 3 encontros & 2 encontros \\
\hline Pensando Políticas Públicas & - & - & - & 2 encontros \\
\hline Total de encontros presenciais & 10 encontros & 6 encontros & 7 encontros & 13 encontros \\
\hline Carga horária total & 180h/aula & 160h/aula & 160h/aula & 140h/aula \\
\hline
\end{tabular}

Por fim o CAAC-SUS surge, conforme a Tabela 2 seguinte, no bojo de um amplo replanejamento nessa capacitação de facilitadores, que durou todo o ano de 2019, construindo uma formação baseada em competências, com cada unidade tendo seus objetivos e indicadores de avaliação, tanto para o curso quanto para o educando, com vistas a possibilitar aos egressos a criação e gestão de Núcleos de Educação Permanente em unidades de saúde da SMS.

Tabela 2. CAAC-SUS na CAEPS-SUS - fase 1 de Capacitação de Tutores e Facilitadores

\begin{aligned} & \hline CURSOS CAAC-SUS \\ & \hline Unidades Educacionais TURMA XXIII \\ & \hline Aprendizagem e Significado 2 encontros \\ & Autonomia e Liberdade 2 encontros \\ & Observação, Reflexão e Expressão 2 encontros \\ & Escuta, Acolhimento e Diálogo 2 encontros \\ & Envolvimento e Transformação 2 encontros \\ & \hline Total de encontros presenciais 10 encontros \\ & Carga horária total $152 \mathrm{~h} /$ aula \\ & \hline\end{aligned}

A mudança nos nomes das Unidades Educacionais visava refletir o que paulatinamente vinha acontecendo durante a evolução dos cursos: em vez de somente se pensar sobre algum tema, as pessoas pensavam, incorporavam ao seu fazer pessoal e o colocavam em prática nas suas unidades de saúde.

A avaliação nos cursos da Fase 1 da CAEPS-SUS, desde seu início, em 2013, sempre foi baseada em critérios, conquistas de aprendizagem a serem realizadas. Essas avaliações ocorriam ao longo do curso, seja nos PR registrados no SEaD entre os encontros presenciais, seja em encontros presenciais de portfólio, individuais ou em grupo. Nesses encontros o facilitador procurava perceber os deslocamentos na construção individual do conhecimento do educando, suas reflexões, conquistas e dificuldades, para dar retornos educacionais com sugestões e reflexões sobre o aprendizado observado.

Essa avaliação tem dois consolidados, denominados de Registros de Avaliação de Desempenho (RAD), um formativo, na metade do curso, e um somativo no último dia de encontro presencial. A certificação no curso se dá por uma frequência de $85 \%$ em encontros presenciais, um RAD somativo satisfatório, demonstrando o deslocamento do aprendizado obtido, em relação aos critérios do curso, e a construção do TCP como trabalho final do curso: uma narrativa reflexiva, escrita em primeira pessoa, sobre toda a trajetória educacional vivida e experienciada. 
O TCP, como processo de conscientização do percurso no curso, ao longo do tempo, passou a ser um diferencial no curso. Escrito como uma síntese que demonstrasse as reflexões e os movimentos de aprendizagem a partir da participação no curso, o TCP deve destacar de onde se partiu, na chegada ao curso, as realizações alcançadas no processo e evidências de onde se chegou, observando-se os diversos objetivos do curso. As evidências e reflexões devem ser fundamentadas e dar visibilidade às mudanças na prática pessoal, sócio-familiar e profissional.

É como que um retorno ao curso, com um novo olhar. Não mais o olhar de quem está iniciando, escrito no PR, mas o olhar de quem já finalizou todas as etapas e olha para o processo e para si mesmo, cabendo por vezes até voltar a literatura, entre as experiências, significados e transformações que foram acontecendo no caminhar consigo mesmo, com o grupo e com o facilitador.

É a última etapa para a certificação. Sabendo que o caminhar nunca se encerra, fica-se apto à Fase 2 do CAEPS-SUS. Atualmente existem 21 facilitadores de Educação Permanente no NEP SAMUFor: 13 atuam diretamente na Estratégia CAEPS-SUS e oito como facilitadores da Educação Permanente do SAMUFor. Do total de 21 facilitadores, três atuam como Tutores no corpo de educadores do NEP SAMUFor.

Hoje, totalmente integrado ao calendário de atividades educacionais da SMS, a Fase 1 já finalizou a sua XXIII turma, tocando e transformando mais de uma centena profissionais de saúde, conforme Tabela 3, onde pode se ver o demonstrativo de egressos certificados:

Tabela 3. Egressos certificados pela fase 1 de Capacitação de Tutores e Facilitadores da CAEPS-SUS

\begin{tabular}{|c|c|c|c|}
\hline \multicolumn{4}{|c|}{ CAPACITAÇÃO DE TUTORES E FACILITADORES } \\
\hline Curso & Ano & Turma & № de TCP \\
\hline \multirow{12}{*}{ MAPEA I } & \multirow{3}{*}{2013} & Turma II & $05 \mathrm{TCP}$ \\
\hline & & Turma III & $05 \mathrm{TCP}$ \\
\hline & & Turma IV & 04 TCP \\
\hline & \multirow{6}{*}{2014} & Turma V & $01 \mathrm{TCP}$ \\
\hline & & Turma VI & $01 \mathrm{TCP}$ \\
\hline & & Turma VII & $01 \mathrm{TCP}$ \\
\hline & & Turma VIII & 00 TCP \\
\hline & & Turma IX & 05 TCP \\
\hline & & Turma X & $04 \mathrm{TCP}$ \\
\hline & \multirow{3}{*}{2015} & Turma XI & 07 TCP \\
\hline & & Turma XII & 12 TCP \\
\hline & & Turma XIII & $02 \mathrm{TCP}$ \\
\hline \multirow{2}{*}{ MAPEA II } & 2016 & Turma XIV & 09 TCP \\
\hline & 2017 & Turma XV & $06 \mathrm{TCP}$ \\
\hline \multirow{3}{*}{ CAS-SUSI } & & Turma XVI & $08 \mathrm{TCP}$ \\
\hline & 2017 & Turma XVII & $10 \mathrm{TCP}$ \\
\hline & & Turma XVIII & $12 \mathrm{TCP}$ \\
\hline \multirow{4}{*}{ CAS-SUS II } & 2018 & Turma XIX & $08 \mathrm{TCP}$ \\
\hline & & Turma XX & 07 TCP \\
\hline & & Turma XXI & $07 \mathrm{TCP}$ \\
\hline & & Turma XXII & 04 TCP \\
\hline \multirow[t]{2}{*}{ CAAC-SUS } & 2020 & Turma XXIII & 08 TCP \\
\hline & & TOTAL & 126 TCP \\
\hline
\end{tabular}




\section{Discussão}

O grande desafio, à época da publicação da Política Nacional de Educação Permanente em Saúde, era a falta de domínio sobre o que era a EPS e como operacionalizá-la. Houve então um grande esforço do Ministério da Saúde, junto com a Escola Nacional de Saúde Pública Sérgio Arouca, na formação descentralizada de quase dez mil trabalhadores em todo o país ${ }^{15}$ (p. 156) como Tutores e Facilitadores de Educação Permanente, em um curso semipresencial com quatro Unidades de Aprendizagem ${ }^{16}$. Tinha-se em mente formar profissionais que conseguissem superar as limitações existentes nos 96 Polos de Educação Permanente em Saúde (PEPS) do país quanto à gestão democrática do trabalho, ante às disputas de poder e controle existentes ${ }^{15}$ (p. 156-157).

Esse processo ocorreu em 2005 e 2006, envolvendo os PEPS e, posteriormente, alguns municípios que optaram por implementar a EPS. Posteriormente, com as novas diretrizes e estratégias de implementação da PNEPS, publicadas em 2007, o curso passou a ser política de formação de profissionais de saúde, visando ampliar a capacidade de implementação da EPS no $\operatorname{SUS}^{16}$ (p. 987).

No NEP SAMUFor, o projeto aplicativo visando a implementação de Educação Permanente como forma de aprimorar a qualidade do serviço, efetuando mudanças organizacionais pela sensibilização, motivação e engajamento de todos os atores a partir do diálogo sobre os problemas da realidade do serviço, trouxe a mesma necessidade de formação de profissionais que facilitassem a "releitura crítica das condições de trabalho, das relações estabelecidas e das necessidades de saúde, levando em conta as particularidades de cada região, dos usuários e dos trabalhadores envolvidos"17 (p. 4684).

Um processo educativo que desse conta dos desafios e demandas do SAMUFor e da necessidade de mudança para novas práticas teria necessariamente de se pautar na EP como estratégia educacional. Embora haja suficiente evidência de que a EPS seja uma prática que possa informar e recriar teorias para que práticas sejam recompostas e recriadas, seja na formação, na atenção, na gestão, na formulação de políticas ou no controle social ${ }^{18}$ (p. 204), a literatura ainda é escassa sobre a EPS em serviços de atendimento pré-hospitalar ${ }^{19}$ (p. 10).

Percebeu-se, nas cinco fases distintas no processo de formação de educadores para a EPS no SAMUFor, representadas pela mudança da nomenclatura dos nomes dos cursos e pelas próprias mudanças estruturais no curso, uma evolução na abordagem metodológica e na ênfase do aprendizado, de uma formação mais técnica, para a implementação da EPS no serviço, para uma formulação mais reflexiva individual, uma reflexão do sujeito enquanto fomentador de mudanças onde quer que esteja.

Passou-se a apostar no desenvolvimento de competências para a criação de vínculo entre os participantes, para promover o desenvolvimento das habilidades de aprender a aprender, da autonomia e aprendizagem colaborativa, para promover a criatividade e, principalmente, para "aprender a Ser para poder ser com os outros como se é consigo mesmo". 


\section{Considerações finais}

Muitas vezes os gestores defendem a EP como prática de qualidade, mas pensam a EP como Educação Continuada ou em Serviço. Mais do que isso, falar de EP é falar de cogestão, pois é um âmbito onde se privilegia o coletivo de pessoas e não somente um indivíduo ou grupo de atores sociais. Ademais, compartilhar saberes significa compartilhar poderes e esse é o elo entre a EP e os dispositivos de cogestão. Por isso também a grande dificuldade na plena implementação da EPS.

Entra-se na seara das subjetividades, das percepções, experiências e significados, dos sistemas explicativos individuais para realidade experienciada, gerando (des)motivações, (des)envolvimentos e transformações que só são possíveis de positividade em um ambiente de observação, reflexão e livre expressão, onde os equívocos sejam acolhidos como parte do aprendizado, onde a democracia do escutar se equipara à democracia do falar, para que o diálogo aconteça e transforme pessoas.

A incorporação da educação permanente ao cotidiano dos serviços de saúde, como uma "forma EP de funcionar" dos mesmos, significa estarmos permanentemente abertos à aprendizagem... permanentemente abertos às mudanças e às transformações. É o estar pronto à instabilidade e à complexidade dos rumos da vida no território de saúde, característica singular das populações, dos coletivos e dos indivíduos.

Espera-se que esse relato de experiência evidencie a necessidade de implementação da EPS inclusive nos serviços de atendimento pré-hospitalar e mostre que o processo de formação de tutores e facilitadores é contínuo, posto que demanda "reformações" à medida que os desafios complexos do cotidiano se reformam e se transformam. 
Contribuição dos autores

Cláudio Roberto Freire de Azevedo participou na concepção e delineamento do trabalho, na obtenção, análise e interpretação dos dados; na discussão dos resultados, na redação do manuscrito e revisão crítica do seu conteúdo e na aprovação da versão final do manuscrito. Juliana Araújo de Medeiros participou na concepção e delineamento do trabalho, na obtenção, análise e interpretação dos dados; na discussão dos resultados e na aprovação da versão final do manuscrito.

Agradecimentos

Núcleo de Educação Permanente do SAMU 192 - Regional Fortaleza

Direitos autorais

Este artigo está licenciado sob a Licença Internacional Creative Commons 4.0, tipo BY-NC (https://creativecommons.org/licenses/by-nc/4.0/deed.pt_BR).

\section{Referências}

1. Fortaleza PM de. Diário Oficial do Município N 15.757, de 29 de abril de 2016 [Internet]. Fortaleza; 2016 [cited 2020 Apr 18]. Available from: https://diariooficial.fortaleza.ce.gov.br/downloaddiario?objectld=workspace://SpacesStore/dd6ec367-0e06-4ba1-8b9e-373101f45120;1.1\&numero=15757

2. Peixoto LS, Gonçalves LC, Costa TD da, Tavares CM de M, Cavalcanti ACD, Elaine Antunes Cortez. Educação permanente, continuada e em serviço: desvendando seus conceitos. Enferm Glob [Internet]. 2013 [cited 2020 Apr 16];29:324-40. Available from: http://scielo.isciii.es/pdf/eg/v12n29/pt_revision1.pdf

3. Núcleo de Educação Permanente. Legislação SAMU 192 - Regional Fortaleza [Internet]. 2019 [cited 2020 Apr 16]. Available from: https://samu.fortaleza.ce.gov.br/index.php/o-samu-192-fortaleza/nucleo-de-ensino/legislacao

4. Brasil M da SS de G do T e da E na SD de G da E em S. Política Nacional de Educação Permanente em Saúde [Internet]. Série B. Textos Básicos de Saúde Série Pactos pela Saúde 2006, v. 9. Brasília: Ministério da Saúde; 2009 [cited 2020 Apr 16]. 64 p. Available from: http://bvsms.saude.gov.br/bvs/publicacoes/pacto_saude_volume9.pdf

5. Carotta F, Kawamura D, Salazar J. Educação permanente em saúde: uma estratégia de gestão para pensar, refletir e construir práticas educativas e processos de trabalhos. Saúde e Soc [Internet]. 2009 [cited 2020 Apr 16];18(supl.1):48-51. Available from: http://www.revistas.usp.br/sausoc/article/view/29529

6. Azevedo CRF de. Aprimoramento da Regulação Médica Primária no Serviço de Atendimento Pré-hospitalar do SAMU 192 em Fortaleza-Ceará, através da Estratégia de Educação Permanente em Saúde [Internet]. [São Paulo]: Instituto Sírio-Libanês de Ensino e Pesquisa; 2012. Available from:

https://www.researchgate.net/publication/350950372_Aprimoramento_da_Regulacao_Medica_Primaria_no_Servic o_de_Atendimento_Pre-hospitalar_do_SAMU_192_em_FortalezaCeara_atraves_da_Estrategia_de_Educacao_Permanente_em_Saude

7. Lopes SRS, Piovesan ÉT de A, Melo L de O, Pereira MF. Potencialidades da educação permanente para a transformação das práticas de saúde. Com Ciências Saúde [Internet]. 2007 [cited 2020 Apr 16];18(2):147-55. Available from: https://pesquisa.bvsalud.org/portal/resource/pt/lil-484725

8. El Hetti LB, Bernardes A, Gabriel CS, Fortuna CM, Maziero VG. Educação permanente/continuada como estratégias de gestão no Serviço de Atendimento Móvel de Urgência. Rev Eletrônica Enferm [Internet]. 2013 Dec 31 [cited 2020 Apr 20];15(4):973-82. Available from: http://revistas.ufg.br/index.php/fen/article/view/24405

9. Jacobovski R, Ferro LF. Educação permanente em Saúde e Metodologias Ativas de ensino: uma revisão sistemática integrativa. Res Soc Dev [Internet]. 2021 Mar 20 [cited 2020 Apr 3];10(3):e39910313391. Available from: https://rsdjournal.org/index.php/rsd/article/view/13391

10. Mitre SM, Siqueira-Batista R, Girardi-de-Mendonça JM, Morais-Pinto NM De, Meirelles CDAB, Pinto-Porto C, et al. Metodologias ativas de ensino-aprendizagem na formação profissional em saúde: debates atuais. Cien Saude Colet [Internet]. 2008 [cited 2020 Apr 16];13(2):2133-44. Available from: http://www.scielo.br/scielo.php?pid=S1413$81232008000900018 \&$ script=sci_abstract \&tlng=pt

11. Berbel NAN. As metodologias ativas e a promoção da autonomia de estudantes. Semin Ciências Sociais e Humanas [Internet]. 2011 [cited 2020 Apr 16];32(1):25-40. Available from: http://www.uel.br/revistas/uel/index.php/seminasoc/article/view/10326

12. Silva GM, Guanaes-Lorenzi C. Registros Reflexivos na Facilitação de Processos de Educação Permanente em Saúde. Rev da SPAGESP [Internet]. 2021 [cited 2020 Apr 20];22(1):6-21. Available from: http://pepsic.bvsalud.org/scielo.php?script=sci_arttext\&pid=S1677-29702021000100002 
13. Núcleo de Educação Permanente. Espiral de Princípios Educacionais do NEP SAMUFor [Internet]. 2021 [cited 2020 May 24]. Available from: https://sead.samu.fortaleza.ce.gov.br/mod/page/view.php?id=221\&forceview=1

14. Fortaleza SM da S de. Plano Municipal de Educação Permanente em Saúde 2018-2021 [Internet]. Timbó MIT, Pinheiro NMM, Albuquerque KM, Maia L de A, Dantas VL de A, Lima R de S, editors. Fortaleza: Secretaria Municipal da Saúde; 2018 [cited 2020 Apr 29]. 98 p. Available from: http://saude.fortaleza.ce.gov.br/2016-

15. Emerson Elias Merhy, Laura Camargo Macruz Feuerwerker, Ricardo Burg Ceccim. Educación Permanente en Salud: una Estrategia para Intervenir en la Micropolítica del Trabajo en Salud. Salud Colect [Internet]. 2006 [cited 2020 Apr 29];2(2):147-60. Available from: http://www.redalyc.org/articulo.oa?id=73120204

16. Nespoli G, Ribeiro VMB. Discursos que formam saberes: uma análise das concepções teóricas e metodológicas que orientam o material educativo de formação de facilitadores de Educação Permanente em Saúde. Interface - Comun Saúde, Educ [Internet]. 2011 Sep 2 [cited 2020 Apr 29];15(39):985-96. Available from:

http://www.scielo.br/scielo.php?script=sci_arttext\&pid=S1414-32832011000400003\&lng=pt\&tlng=pt

17. Laprovita D, Fernandes FC, Almeida LP de, Corvino MPF, Cortez EA, Braga AL de S. Educação permanente no atendimento pré-hospitalar móvel: perspectiva de Emerson Merhy. Rev Enferm UFPE line [Internet]. 2016 Nov 15 [cited 2020 Apr 20];10(12):4680-6. Available from:

https://periodicos.ufpe.br/revistas/revistaenfermagem/article/view/11538

18. Garcia CA, Meneguci J, Bastos MAR. Ações de Educação Permanente na Saúde Pública Brasileira: uma revisão integrativa. REFACS (online) [Internet]. 2015 Jul 13 [cited 2020 Apr 29];3(3):194-205. Available from: http://seer.uftm.edu.br/revistaeletronica/index.php/refacs/article/view/1237

19. Fernandes FC, Laprovita D, Bonin WL de M, Valente GSC, Cortez EA, Corvino MPF. Permanent Education in the emergency mobile pre-hospital care service: an integrative review. Online Brazilian J Nurs [Internet]. 2020 Sep 2 [cited 2020 Apr 20];19(2):13. Available from: http://www.objnursing.uff.br/index.php/nursing/article/view/5928 


\section{ABSTRACT}

Objective: this study aims to present the evolution of methodological changes in the training of professionals for permanent health education. Methodology: this is a descriptive study, of a qualitative nature, based on documentary analysis on the Training of Tutors and Facilitators in Permanent Education in Health at SUS, carried out by the Núcleo de Educação Permanente of SAMU 192 Regional Fortaleza since January 2013, training health professionals to facilitate permanent education in their services. Results: the training went through five phases over time, integrating itself as an educational activity of the Municipal Health Secretariat of Fortaleza and driving the construction of the Municipal Plan for Permanent Education in Health. Final considerations: an evolution in the methodological approach was noticed and in the emphasis on learning, from a more technical training, to the implementation of Permanent Education in Health in the service, to an individual reflective training, a reflection of the subject as a promoter of changes wherever he is. It started to promote the development of the skills of learning to learn, of autonomy and collaborative learning, to promote creativity and, mainly, to "learn to Be in order to be with others as one is with oneself".

Descriptors: Teacher Training; Continuing Education; Emergency Medical Services. Keywords: Training of Facilitators; Permanent Education; Urgency; Prehospital.

\section{RESUMEN}

Objetivo: este estudio tiene como objetivo presentar la evolución de los cambios metodológicos en la formación de profesionales para la educación permanente en salud. Metodología: se trata de un estudio descriptivo, de carácter cualitativo, basado en el análisis documental sobre la Capacitación de Tutores y Facilitadores en Educación Permanente en Salud en el SUS, realizado por el Núcleo de Educação Permanente del SAMU 192 Regional Fortaleza desde enero de 2013, capacitación profesionales de la salud para facilitar la educación permanente en sus servicios. Resultados: la capacitación pasó por cinco fases, integrándose como una actividad educativa de la Secretaría Municipal de Salud de Fortaleza e impulsando la construcción del Plan Municipal de Educación Permanente en Salud. Consideraciones finales: había una evolución en el enfoque metodológico y en el énfasis en el aprendizaje, desde la formación más técnica, a la implementación de la Educación Permanente en Salud en el servicio, a una formación reflexiva individual, reflejo del sujeto como promotor de cambios allá donde se encuentre. Comenzó a promover el desarrollo de las habilidades de aprender a aprender, de la autonomía y el aprendizaje colaborativo, a promover la creatividad y "aprender a Ser para estar con los demás como con uno mismo".

Descriptores: Formación del Profesorado; Educación Permanente; Servicios Médicos de Urgencia.

Palabras clave: Formación de facilitadores; Educación permanente; Urgencia; Prehospitalario. 